\title{
Validation of the Flow Scale Related to Physical Education in Arabic Language
}

\author{
Mouna Abbassi ${ }^{*}$, Walid Abbassi ${ }^{2}$, Fabien Fenouillet ${ }^{3}$, Abdelmajid Naceur ${ }^{4}$ \\ ${ }^{1}$ Didactics of Physical and Sport Activities, Tunis, Tunisia \\ ${ }^{2}$ Computer Science: Modeling of Automatic Reasoning Systems, Mounastir, Tunisia \\ ${ }^{3}$ Positive Learning Psychology, Interdisciplinary Laboratory in Neuroscience, Physiology and Psychology Learning, Physical \\ Activities and Health (LINP2-2APS), University of Paris Nanterre, Paris, France \\ ${ }^{4}$ Cognitive Psychology, Research Unit Director “ECOTIDI”, Tunis, Tunisia \\ Email: *abbassi_mounaspt@yahoo.fr
}

How to cite this paper: Abbassi, M., Abbassi, W., Fenouillet, F., \& Naceur, A. (2021). Validation of the Flow Scale Related to Physical Education in Arabic Language. Advances in Physical Education, 11, 246-260.

https://doi.org/10.4236/ape.2021.112020

Received: February 28, 2021

Accepted: May 11, 2021

Published: May 14, 2021

Copyright $\odot 2021$ by author(s) and Scientific Research Publishing Inc. This work is licensed under the Creative Commons Attribution International License (CC BY 4.0).

http://creativecommons.org/licenses/by/4.0/

(c) (i) Open Access

\begin{abstract}
Objective: Develop and test psychometric properties of the academic flow instrument in physical education. Methods: A total of 654 retained participants aged between 10 and 18 completed the four-dimensional Physical Education Flow Questionnaire (PHFLOW) (134 in the exploratory phase and 520 in the confirmatory phase). The participants in the first exploratory study were female $(\mathrm{n}=69)$ and male $(\mathrm{n}=65)$ attending primary school $(\mathrm{n}=32.84 \%)$, college $(40.30 \%)$ and secondary school (26.87\% studies). The 520 have a mean age of $14.13 \pm 2.61$ years. Male students presented $52.7 \%$ of the participants (mean age 14.20 ; $\mathrm{SD}=2.60$ ), whereas $47.53 \%$ were female (mean age 14.03 ; $\mathrm{SD}=2.63$ ). The percentages of students are respectively: $33.1 \%(n=172), 36.3 \%(n=189)$ and $30.6 \%(n=159)$ for primary, college and secondary. Results: The result of exploratory and confirmatory factor analysis, as well as the analysis of reliability through the internal consistency index proved the robustness of the measurement instrument. The concurrent validity of the instrument was satisfactory, on the one hand by a significant negative relationship between autotelic experience and PANAS negative affect, and on the other hand by a significant positive relationship between autotelic experience and PANAS positive affect. Conclusion: The PH-Flow scale can administer to assess academic flow in physical education.
\end{abstract}

\section{Keywords}

Flow, Sport and Physical Education, Questionnaire

\section{Introduction}

In recent decades, a plethora of studies have emphasized the importance of reg- 
ular physical activity in children and adolescents (Farooq et al., 2020; Oh et al., 2020; Wilson \& Barnett, 2020; Messing et al., 2019) and its positive impact in both their physical (Cairney et al., 2019) and mental health (Biddle et al., 2019; Rodriguez-Ayllon et al., 2019). Thus, the World Health Organization recommends 60 minutes of regular physical activity every day for children aged between 5 and 17 years (Sember et al., 2018). However, nowadays, in family and at school environment children often experience a lack of physical exercise and an abundance of sedentary behavior. Physical and sport education in school settings has been shown to have a significant impact on classroom behavior, self-esteem, self-image, and cognitive function. Therefore, student engagement, enjoyment and pleasure in school physical practice were highly recommended. Flow theory was used as a concept that characterizes an experience of state of consciousness where the person fully immerses himself in an activity and actively benefits from it. Indeed, it was initially described by Csikszentmihaly, et al., (Csikszentmihalyi, Abuhamdeh, \& Nakamura, 1990) as an optimal experience during which people are deeply motivated to persist in their activities.

The experience of flow can be presented in a variety of activities, including playing music, creating artistic activities, sports and even in the context of work (Jackson et al., 1998; Salanova, Bakker, \& Llorens, 2006) including learning and other academic activities (Rijavec, Golub, \& Olčar, 2016; Rijavec \& Belina, 2018). Since November 2014, the European Flow Researchers Network has proposed the following consensus definition: "it is a state of fulfillment linked to the deep involvement and the sense of absorption that people feel when they are confronted with tasks with high demands and when they perceive that their skills allow them to meet these challenges".

In the academic context, flow theory was used as a useful framework to explain student engagement and enjoyment in learning (Naceur \& Schiefele, 2005).

Flow was liked to increased motivation, better competition and growth in individual abilities.

As flow theory would predict, flow has been found to be related to higher student engagement, exams (Shernoff \& Csikszentmihalyi, 2009), better progress in the school curriculum (Csikszentmihalyi, Rathunde, \& Whalen, 1993), a GPA (Golub, Rijavec, \& Olčar, 2016) and better performance (Engeser et al., 2005; Naceur, 2010).

The characteristics of the flow state include the enjoyment in an activity, the focus of attention and the absorption in the activity, the loss of self and the feeling to be in control of one's actions (Csikszentmihalyi, Abuhamdeh, \& Nakamura, 1990).

Several scales were designed to measure the flow in several areas. Since the initial work of Mayers (Mayers, 1978) who developed the first questionnaire to measure flow on 12 items with a differential semantic scale. Other generalized works on populations in real life (Bakker, 2008; Martin \& Jackson, 2008), and virtual communities (Witmer \& Singer, 1998; Chen, Wigand, \& Nilan, 1999; Choi \& Kim, 2004; Kiili \& Lainema, 2008) were proposed to measure the concept of positive psychology. 
A work of Jakson and March (Jackson \& Marsh, 1996) allowed the development of a long scale of 36 items to measure the concept in the context of sport and physical education. The Flow State Scale (FSS) was validated and empirically tested only on athletes. Subsequently, another shorter version of a 9-items Flow was developed and empirically validated by Jackson and Eklund (Jackson \& Eklund, 2002). In another work of Payne et al., (Payne et al., 2011), an attempt to adapt the FSS scale was carried out to generalize the items to several non-sport populations. The psychometric properties were satisfactory.

In another paper by Rheinberg, et al., (Rheinberg, Vollmeyer, \& Engeser, 2003) a short scale of 13 items assessed on a 7 points Likert scale was developed to measure two aspects of the Flow experience. In particular, the scale incorporated 3 items that were able to measure the effects of the experience.

In the academic field, few works have attempted to examine the concept. The work of developing an instrument of measuring Flow in an academic context was done by Suk and Kang (Suk \& Kang, 2007) who validated the learning Flow Scale composed of 30 items on Korean high school students. The most interesting work in the educational context is that of Heutte, et al., (Heutte et al., 2014) who evaluated the Flow in "the educational context". Hence, the construction of a new flow scale (EduFlow). Indeed, an evolution of the flow measurement scale was carried out by Heutte, et al., (Heutte et al., 2014; Heutte et al., 2016b) by reducing the dimensions of the flow for a better relevance of cognitive process, therefore this scale contains only 12 items. This new scale validated and tested in schools and universities (Heutte et al., 2016a). The tool was made it possible to measure flow and its effects.

In the Arab world, only one work was carried out to validate an instrument for measuring Academic Flow Chalghaf, et al., (Chalghaf, Azaiez, Krakdiya, et al., 2019) validated a version of academic Flow questionnaire with 4 factors and 16 items on a population of university student in Tunisian physical education and sport. No scale has been adapted in the context of physical education as a subject of instruction for school children.

The objective of the present study was to develop and validate an instrument of academic flow in the context of physical education and sports and to verify its psychometric properties through two exploratory and confirmatory samples.

\section{Methodology}

\subsection{Ethical Considerations}

For the present study, the participation in the study conforms to the ethical standards of the 1975 Helsinki Declaration and in accordance with ethical conventions of the research protocols of the Tunisian University in Educational Sciences.

No financial, academic offer was made to participants who contributed voluntarily to the study. 


\subsection{Participants}

A total of 711 students were recruited for this study. The subjects attend primary, basic and secondary education and all practice regular physical education in public institutions. They all belong to the northwestern region of Tunisia. As an inclusion criterion, it was established that the participants have no absence in the practical sessions of unjustified physical activity and sport from the beginning of the school year in particular at least two years of study. A native language other than Arabic and a minimum age of 10 and a maximum age of 18 were set as exclusion criteria. As a result, 57 students were excluded, so the total number of participants in the study was 654. The participants in the first exploratory study were female $(\mathrm{n}=69)$ and male $(\mathrm{n}=65)$ following primary $(\mathrm{n}=$ $32.84 \%)$, basic $(40.30 \%)$ and secondary $(26.87 \%)$ studies. The participants in this preliminary study aged between 10 and 18 years (average $=13.77, \mathrm{SD}=2.60$ ). The participants in the confirmatory study are 520 with an average age of 14.13 \pm 2.61 . Male students presented $52.7 \%$ of the participants (average age 14.20 , SD $=2.60$ ), while $47.53 \%$ were female (average age $14.03, \mathrm{SD}=2.63$ ). The percentages of students are 33.1\% $(n=172), 36.3 \%(n=189)$ and $30.6 \%(n=159)$ for primary, college and secondary respectively.

\subsection{Instrument}

A translated Arabic version suitable for the physical and sports education context of Eduflow was used to measure the PH-FLOW Academic Flow. The initial instrument that assesses Flow in the academic context was designed and tested empirically in various real and virtual communities on large samples with students in primary, secondary and university schools. Also, two scaling modalities have been examined in empirical research including face-to-face learning (Fenouillet et al., 2014) and learning in the virtual context (Bellotti et al., 2014; Heutte et al., 2014).

The instruments are made up of 4 dimensions: cognitive control (D1), immersion and alteration of the perception of time (D2), lack of concern about the self (D3), and the autotelic experience which explains the well-being provided by the activity itself (D4). Each of these four dimensions is made up of 3 items which are measured on a 7 point Likert Scale.

The first three dimensions (D1 + D2 + D3) for the cognitive absorption, this fundamental determinant of the persistence to want to understand, as well as of the quality of learning induced by this persistence.

Positive and Negative Affect Schedule Scale (Narayanan et al., 2020)

The 20-items of positive and Negative Affect Schedule Scale (PANAS) in Arabic Language questionnaire was validated on 340 students' followings a comparison of three models with one, two and three factors. The tool assesses two dimensions of positive and negative emotions. The positive Affects (PA) scale measured by 10 items and reflects the level of pleasurable engagement, the extent to which a person feels enthusiastic, excited, active and determined. Like- 
wise, the Negative Affects Scale (PN) reflects a general dimension of unpleasant engagement and subjective distress that encompasses a wide range of aversive affects, including fear, nervousness, guilt, and shame. The items are presented in easy, understandable words and measured on a 5-point Likert Scale.

After the confirmatory factor analysis, the two-factor model was retained for indices of modest adjustments (CFI $=0.84$, and TLI $=0.87$, RMSEA $>0.80$ ). Likewise, the internal consistency measured by Cronbach's alpha for the PA and NA subscales were acceptable (alpha $=0.72$ and alpha $=0.79$, respectively). This is probably due to the reduced number of participants.

\subsection{Procedures}

A translation committee was formed by a professional translator, two Arabic language teachers, two French teachers, two humanities academics and translation expert. The committee developed an initial version in Arabic. The reverse translation as recommended by Maneesriwongul and Dixon (Maneesriwongul \& Dixon, 2004) led to a very similar version of the original. The committee formulated a 12-item experimental version of the original PH-Flow. Then, the team suggested the adaptations of the questionnaire to the context of physical education. The developed version carefully checked whether the meaning of the statements had been well preserved to measure the four dimensions of PH-Flow by ensuring that each item conveyed the meaning best suited to the meaning of original version of the tool that measure the Academic Flow. After this step, 22 teachers of different sports disciplines and who practice their teaching activities of practical sessions of physical education and sport in primary, secondary and higher establishments evaluated whether three ambiguities in the items on a 5-point grid ranging from (no ambiguity to very ambiguous). The members did not propose any suggestions or modifications to the instruments.

Two assignments were carried out just at the end of the practical sessions of physical education and sports at an interval of one month on two different groups were carried out after the agreements granted by the school directors. The first test was carried out on an exploratory sample for one week, while the second test on the confirmatory sample of PH Flow and PANNAS questionnaire was carried out over a period of 3 weeks at the end of the physical education sessions.

\subsection{Statistical Tools}

All statistics were compiled using IBM SPSS version 26 and SPSS Amos version 21. The significance levels were set at 0.05. All descriptive statistics were represented by means \pm Standard deviations for the four dimensions of the measurement scale, and the items normality was examined by the Kurtosis and Skewness indices.

The factor structure of $\mathrm{PH}-$ Flow was determined by an exploratory factor analysis using a principal component analysis with Eigenvalues greater than 1 
and Promax rotation as recommended by Bourque, et al., (Bourque, Poulin, \& Cleaver, 2006) for correlated factors. In addition, the Kaiser Meyer-Olkin factorization potential index (KMO) which has a minimum threshold of 0.6 and the test of significant Bartlett sphericity were considered.

Cronbach's alpha coefficient was used to measure the reliability of internal consistency, with a value $>0.70$ considered as a minimum threshold for measuring internal consistency (Nunnally \& Bernstein, 1994).

The reliability of instrument was examined for the confirmatory sample by Cronbach's $\alpha$ coefficient, Mc Donald's $\omega$ coefficient and Gutmann's $\lambda 6$. Likewise, a first-order confirmatory factor analysis for the instrument and the model of relationships between components was performed.

The confirmatory factor analysis for the model and the verification of the adjustment indices was carried out through the following indices:

1) The chi-square test which must be insignificant for a good fit of the model. However, the index is very sensitive to sample size and highly criticized in the literature. Another index that is used a lot is 2) the Chi-square divided by the value of the degrees of freedom ( $\mathrm{df}$ ) should be less than 5 and have an ideal threshold less than 2.3) The GFI is a measure of quantity relative variance taken into account by the model; while 4) the AGFI also takes into account the parsimony of the model. Regarding the cut-off values for information theory fit measures, the value of GFI and AGFI should be respectively greater than 0.95 and 0.90 (Byrne, 1994). 5) The NFI should exceed the minimum threshold of 0.59 according to Schumacker and Lomax (Schumacker \& Lomax, 2004). 6) Bentler's comparative goodness index or CFI would have to exceed 0.95 to accept the model (Bentler, 1990; Hu \& Bentler, 1999). Likewise, 7) the Tuker-Lewis goodness-of-fit index (TLI) is recommended to be greater than or equal to 0.95 . 8) The RMSEA approximation error evaluates the lack of fit of the model to the population covariance matrix, the values less than 0.08 are acceptable, and an acceptable fit (Browne \& Cudeck, 1993).

The concordant validity of the instrument was achieved by examining the correlations between PANAS and D4.

\section{Results}

Table 1 presents the results of descriptive statistics, and normality Skewness and Kurtosis coefficients of exploratory samples.

The varimax-type orthogonal factor analysis (Kaiser, 1958) was performed on the responses of the first sample.

The Kaiser-Meyer-Olkin sampling precision measure index yields a value of 0.79 and Bartlett's sphericity test yields a chi-square value $=829.337 ; \mathrm{df}=66$; highly significant at $p<0.001$.

The principal component analysis allowed us to extract four components explaining respectively for the factors from 1 to $4: 40.48 \%$ (eigenvalue $=4.86$ ), $15.47 \%$ (eigenvalue $=1.89), 11.35 \%($ eigenvalue $=1.36)$ and $9.49 \%($ eigenvalue $=$ 1.14) of the total explained variance. 
Table 1. Descriptive statistics and normality of the exploratory sample.

\begin{tabular}{lcccc}
\hline & Moyenne & Ecart type & Skewness & Kurtosis \\
\hline D1A & 5.00 & 1.88 & -0.75 & -0.55 \\
D1B & 4.81 & 1.62 & -0.43 & -0.52 \\
D1C & 5.01 & 1.77 & -0.65 & -0.52 \\
D2A & 5.17 & 1.73 & -0.78 & -0.30 \\
D2B & 5.19 & 1.74 & -0.65 & -0.77 \\
D2C & 5.21 & 1.89 & -0.81 & -0.55 \\
D3A & 5.17 & 1.86 & -0.80 & -0.54 \\
D3B & 5.29 & 1.83 & -0.81 & -0.49 \\
D3C & 5.15 & 1.73 & -0.92 & 0.03 \\
D4A & 5.09 & 1.69 & -0.72 & -0.37 \\
D4B & 4.79 & 1.75 & -0.42 & -0.82 \\
D4C & 4.77 & 1.75 & -0.39 & -0.86 \\
\hline
\end{tabular}

Table 2 shows the factorial loadings of the four components extracted from the adapted scale. No item was deleted from the component matrix.

The results of internal consistency on exploratory sample indicate that the four dimensions of the scale have good internal consistency: alpha $=0.81$, alpha $=0.87$, alpha $=0.85$ and alpha $=0.85$ for D1, D2, D3 and D4 respectively.

\subsection{Descriptive Statistics and Normality of Confirmatory Sample}

Table 3 shows descriptive statistics and normality coefficients of confirmatory sample. The univariate and multivariate normality of the distributions was examined by the Skew and Kurtois indices. The univariate Kurtosis indices are between -1 and 1 as recommended by Tabachnick and Fidell (Tabachnick \& Fidell, 2007). Likewise, the Multivariate Kurtosis Index showed adequate value equal to 9.98 .

\subsection{Internal Consistency for the Confirmatory Sample}

The reliability of the instrument was examined for the confirmatory sample by Cronbach's a coefficient, McDonald's $\omega$ coefficient and Gutmann's $\lambda 6$ (Cronbach, 1951; McDonald, 1970; Guttman, 1945). Table 4 (internal consistency for the confirmatory sample) shows the coefficients of reliability for the four factors of the instrument. All indices show good reliability for the various factors of the scale 7 .

The model of the 4-factor instrument is illustrated in Figure 1. The adjustment indices provided by the first-order factor analysis were consistent with the theoretical recommendations for accepting a model. The KHI2 $=156.11(p<$ $0.01), \mathrm{KH} 2 / \mathrm{DDL}=3.25, \mathrm{GFI}=0.95, \mathrm{AGFI}=0.92, \mathrm{RMSEA}=0.066, \mathrm{NFI}=0.95$, $\mathrm{TLI}=0.95$, CFI $=0.96$. As shown in Figure 2, all standardized factor loadings were greater than 0.73 and significant $(p<0.01)$.

The adjustment indices were acceptable to explain the model condition/effect: 
Table 2. Matrix of components extracted from the four factors.

\begin{tabular}{llccc}
\hline & Factor & Factor2 & Factor 3 & Factor4 \\
\hline D1A & & & & 0.86 \\
D1B & & & 0.74 \\
D1C & & & 0.81 \\
D2A & 0.85 & & \\
D2B & 0.88 & & \\
D2C & 0.81 & & \\
D3A & & 0.76 & & \\
D3B & & 0.84 & & \\
D3C & & 0.85 & & \\
D4A & & & 0.78 & \\
D4B & & & 0.90 & \\
D4C & & & & \\
\hline
\end{tabular}

Table 3. Normality of items on the confirmatory sample.

\begin{tabular}{ccccccc}
\hline Variables & Mean & SD & Skew & c.r. & Kurtosis & c.r. \\
\hline D1A & 3.66 & 1.64 & -0.01 & -0.04 & -0.58 & -2.71 \\
D1B & 3.77 & 1.52 & 0.01 & 0.13 & -1 & -4.68 \\
D1C & 3.83 & 1.61 & 0.03 & 0.31 & -0.96 & -4.48 \\
D2A & 3.85 & 1.60 & 0.16 & 1.49 & -0.73 & -3.39 \\
D2B & 4.06 & 1.79 & 0.23 & 2.15 & -0.64 & -2.97 \\
D2C & 4.18 & 1.82 & 0.12 & 1.09 & -0.87 & -4.03 \\
D3A & 3.71 & 1.52 & 0.15 & 1.41 & -0.87 & -4.04 \\
D3B & 3.72 & 1.49 & 0.04 & 0.40 & -0.92 & -4.28 \\
D3C & 3.65 & 1.69 & 0.06 & 0.56 & -0.76 & -3.53 \\
D4A & 3.62 & 1.54 & -0.05 & -0.50 & -0.85 & -3.95 \\
D4B & 3.68 & 1.57 & 0.01 & 0.05 & -0.67 & -3.10 \\
D4C & 3.48 & 1.54 & 0.19 & 1.76 & -0.71 & -3.31 \\
Multivariate & & & & & 9.98 & 6.21 \\
\hline
\end{tabular}

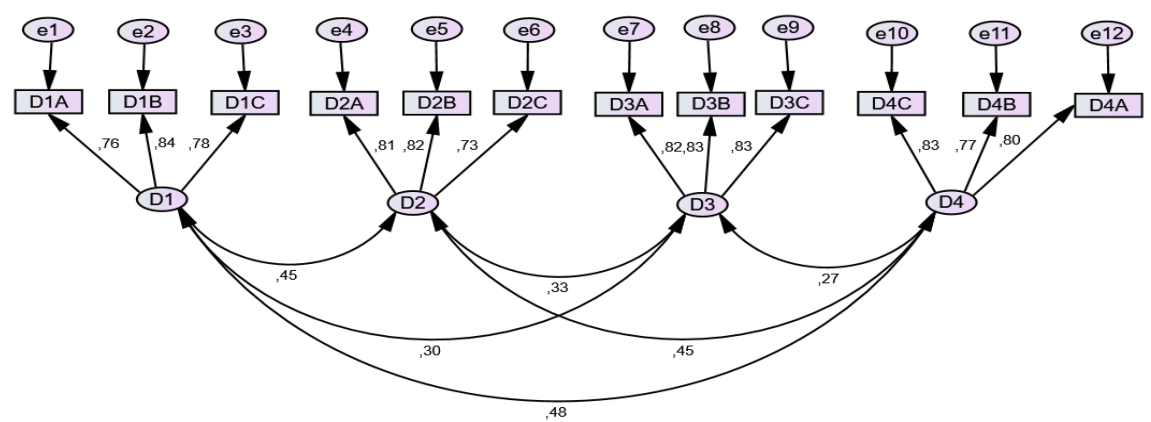

Figure $1.1^{\text {st }}$ order factor model of the flow questionnaire in physical education in Arabic. 
Table 4. Internal consistency for the confirmatory sample.

\begin{tabular}{cccc}
\hline Dimensions & McDonald's $\omega$ & Cronbach's $\alpha$ & Gutmann's $\lambda 6$ \\
\hline D1 & 0.837 & 0.835 & 0.774 \\
D2 & 0828 & 0.835 & 0.764 \\
D3 & 0.866 & 0.865 & 0.81 \\
D4 & 0.844 & 0.843 & 0.783 \\
\hline
\end{tabular}

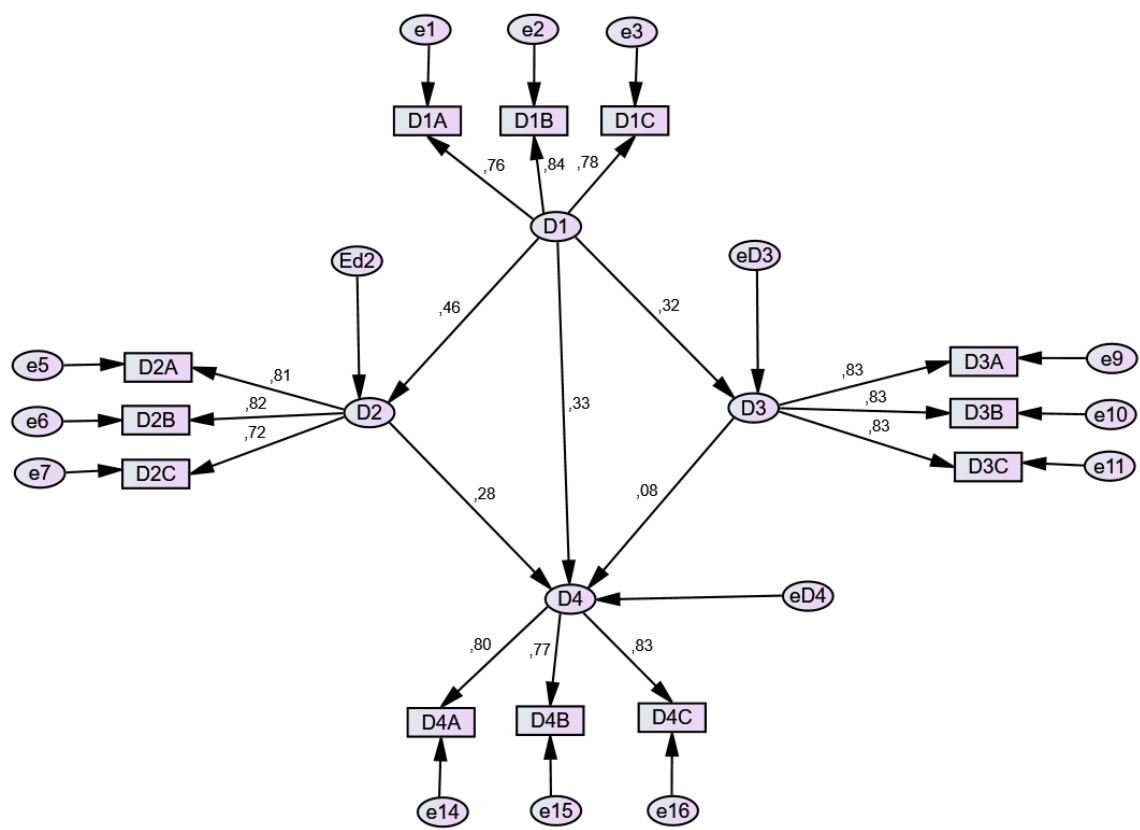

Figure 2. First-order factorial model of the relationship between the dimensions of the Flow questionnaire in Physical Education in Arabic.

$$
\text { KHI2 }=192.95(p<0.01), \mathrm{KH} 2 / \mathrm{DDL}=\mathrm{GFI}=0.95, \mathrm{AGFI}=0.91, \mathrm{RMSEA}=
$$
$0.07, \mathrm{NFI}=0.93$, TLI $=0.94, \mathrm{CFI}=0.96$. As shown in Figure 2, all standardized factor weights were greater than 0.72 and significant $(p<0.01)$.

The linear coefficients $r^{2}$ between the dimensions D1/D2, D1/D3 and D1/D4 were $0.32,0.46$ and 0.33 respectively, which indicates that cognitive absorption could explain $32 \%, 46 \%$ and $33 \%$ of the variance of the autotelic experience. Also, D2 and D3 explained $28 \%$ and $8 \%$ (weak indicator) of the autotelic experience respectively.

\subsection{Concurrent Validity}

To test concurrent validity, we performed the Pearson correlation between the autotelic experience of Flow and the positive and negative affect measured on the PANAS scale.

The results indicated a very significant negative correlation between autotelic experience (D4) and negative affect $\left(\mathrm{r}^{2}=-0.33 ; p<0.01\right)$. While a very significant positive correlation was demonstrated between the autotelic experience (D4) and the positive affect measured on the PANAS scale $\left(r^{2}=-0.33 ; p<0.01\right)$. 


\section{Discussion}

The objective of the present study was to develop and validate an instrument of academic flow in the context of physical education and sport and to verify its psychometric properties through two exploratory and confirmatory samples. The results of the exploratory and confirmatory factor analysis, as well as the analysis of the reliability through the internal consistency index proved the robustness of the measurement instrument. Also, linear regressions showed significant effects of cognitive absorption (D1, D2 and D3) on the autotelic experience (D4). The concurrent validity of the instrument was satisfactory, on the one hand by a significant negative relationship between the autotelic experience and the negative effect, and on the other hand by a significant positive relationship between the autotelic experience and the positive affect.

Our results are in the line with those of the results collected on the initial version by Heutte, et al., (Heutte et al., 2016b) who found good fit indices by the confirmatory factor analysis: $\mathrm{CFI}=0.99$; TLI $=0.98$; RMSEA $=0.053$; $\mathrm{SRMR}=$ 0.03. Also, as for our population, the relationship between the dimensions of the model presented linear regression coefficients similar to those of the study for a real community and online courses.

Several validations and cross-cultural validations have been carried out and linked to the context of sport and physical education such as the example of Jackson and Eklund (Jackson \& Eklund, 2002) who validate a second-order measurement of flow linked to physical activity and which show signs of adequate adjustment.

In another study Payne, et al., (Payne et al., 2011) validate a Flow scale that was adapted from the Flow State Scale (FSS); and representing nine dimensions of flow. The scale was developed to adapt the FSS model for generalization across activities and populations. The authors suggested that items can be deleted or replaced if they do not suit the context (Vollmeyer \& Rheinberg, 2006).

A major problem arises in our study. However, the two activities: sport and physical activities, have been cited in various works without taking into account the specificity of each. Thus, the Flow experience is considered the same during both activities. So, there are big differences between sport and physical education. Indeed, physical education is a school discipline which aims to develop the motor performance of students both cognitive and socio-affective dimension. This discipline, sometimes based on non-sporting games, seeks to improve the learning of motor skills. Also, this discipline highlights the differences between students' skills and their levels of learning. Physical activity in primary schools usually takes the form of games where sporting regulations are almost absent. On the other hand, in the field of sport, the search for better performance is the main goal of the coach as well as the athlete. So, the player practices many training sessions with very high frequency and intensity.

\section{Limit of the Study}

Like all research work, this work has limitations 1) The examination of the rela- 
tionships between the dimensions of Flow with motivation and academic effectiveness in physical education has not been carried out. 2) The concurrent validity for the cognitive absorption dimensions could not be demonstrated since a scale appropriate to the context and the population could not be found.

\section{Conclusion}

In conclusion, the adapted version of the Academic Flow in Physical Education can be used by teachers of physical activities and sports to assess the concept. However, more work is needed to test the concept on other populations and languages. It is also recommended to see the impact of this flow on the performance achieved in physical education and on school performance in general.

\section{Conflicts of Interest}

The authors declare no conflicts of interest regarding the publication of this paper.

\section{References}

Bakker, A. B. (2008). The Work-Related Flow Inventory: Construction and Initial Validation of the WOLF. Journal of Vocational Behavior, 72, 400-414. https://doi.org/10.1016/j.jvb.2007.11.007

Bellotti, F., Bottino, R. M., Fernández-Manjón, B., \& Nadolski, R. (2014). Guest Editorial: Game Based Learning for 21st Century Transferable Skills: Challenges and Opportunities. Journal of Educational Technology \& Society, 17, 1-2.

Bentler, P. M. (1990). Comparative Fit Indexes in Structural Models. Psychological Bulletin, 107, 238-246. https://doi.org/10.1037/0033-2909.107.2.238

Biddle, S. J., Ciaccioni, S., Thomas, G., \& Vergeer, I. (2019). Physical Activity and Mental Health in Children and Adolescents: An Updated Review of Reviews and an Analysis of Causality. Psychology of Sport and Exercise, 42, 146-155. https://doi.org/10.1016/j.psychsport.2018.08.011

Bourque, J., Poulin, N., \& Cleaver, A. (2006). Évaluation de l'utilisation et de la présentation des résultats d'analyses factorielles et d'analyses en composantes principales en éducation. Revue des sciences de l'éducation, 32, 325-344. https://doi.org/10.7202/014411ar

Browne, M. W., \& Cudeck, R. (1993). Alternative Ways of Assessing Model Fit. In K. A. Bollen, \& J. S. Long (Eds.), Testing Structural Equation Models (pp. 136-162).

Byrne, B. M. (1994). Structural Equation Modeling with EQS and EQS/Windows: Basic Concepts, Applications, and Programming. Sage.

Cairney, J., Dudley, D., Kwan, M., Bulten, R., \& Kriellaars, D. (2019). Physical Literacy, Physical Activity and Health: Toward an Evidence-Informed Conceptual Model. Sports Medicine, 49, 371-383. https://doi.org/10.1007/s40279-019-01063-3

Chalghaf, N., Azaiez, C., Krakdiya, H., Guelmami, N., Re, T. S., Maldonado Briegas, J. J. et al. (2019). Trans-Cultural Validation of the "Academic Flow Scale" (Flow 4D 16) in Arabic Language: Insights for Occupational and Educational Psychology from an Exploratory Study. Frontiers in Psychology, 10, 2330. https://doi.org/10.3389/fpsyg.2019.02330

Chen, H., Wigand, R. T., \& Nilan, M. S. (1999). Optimal Experience of Web Activities. 
Computers in Human Behavior, 15, 585-608. https://doi.org/10.1016/S0747-5632(99)00038-2

Choi, D., \& Kim, J. (2004). Why People Continue to Play Online Games: In Search of Critical Design Factors to Increase Customer Loyalty to Online Contents. CyberPsychology \& Behavior, 7, 11-24. https://doi.org/10.1089/109493104322820066

Cronbach, L. J. (1951). Coefficient Alpha and the Internal Structure of Tests. Psychometrika, 16, 297-334. https://doi.org/10.1007/BF02310555

Csikszentmihalyi, M., Abuhamdeh, S., \& Nakamura, J. (1990). Flow.

Csikszentmihalyi, M., Rathunde, K. R., \& Whalen, S. (1993). Talented Teenagers: A Longitudinal Study of Their Development. Cambridge: Cambridge University Press.

Engeser, S., Rheinberg, F., Vollmeyer, R., \& Bischoff, J. (2005). Motivation, Flow-Erleben und Lernleistung in universitären Lernsettings. Zeitschrift für Pädagogische Psychologie, 19, 159-172. https://doi.org/10.1024/1010-0652.19.3.159

Farooq, A., Martin, A., Janssen, X., Wilson, M. G., Gibson, A. M., Hughes, A., \& Reilly, J. J. (2020). Longitudinal Changes in Moderate-to-Vigorous-Intensity Physical Activity in Children and Adolescents: A Systematic Review and Meta-Analysis. Obesity Reviews, 21, e12953. https://doi.org/10.1111/obr.12953

Fenouillet, F., Martin-Krumm, C., Jean, H., \& Besançon, M. (2014). An Urgent Call for Change: Flow, Motivation and Wellbeing in French School Student. 7th European Conference on Positive Psychology, Amsterdam, July 2014.

Golub, T. L., Rijavec, M., \& Olcar, D. (2016). The Relationship between Executive Functions and Flow in Learning. Studia Psychologica, 58, 47-58.

https://doi.org/10.21909/sp.2016.01.706

Guttman, L. (1945). A Basis for Analyzing Test-Retest Reliability. Psychometrika, 10, 255-282. https://doi.org/10.1007/BF02288892

Heutte, J., Fenouillet, F., Boniwell, I., Martin-Krumm, C., \& Csikszentmihalyi, M. (2014). Optimal Learning Experience in Digital Environments: Theoretical Concepts, Measure and Modelisation. In Symposium "Digitial Learning in 21st Century Universities”. Atlanta, GA: Georgia Institute of Technology (Georgia Tech).

Heutte, J., Fenouillet, F., Kaplan, J., Martin-Krumm, C., \& Bachelet, R. (2016a). The EduFlow Model: A Contribution toward the Study of Optimal Learning Environments. In L. Harmat, F. Ørsted Andersen, F. Ullén, J. Wright, \& G. Sadlo (Eds.), Flow Experience (pp. 127-143). Cham: Springer. https://doi.org/10.1007/978-3-319-28634-1 9

Heutte, J., Fenouillet, F., Martin-Krumm, C., Boniwell, I., \& Csikszentmihalyi, M. (2016b). Proposal for a Conceptual Evolution of the Flow in Education (EduFlow) Model. In 8th European Conference on Positive Psychology (ECPP 2016), Angers, June 2016.

Hu, L. T., \& Bentler, P. M. (1999). Cutoff Criteria for Fit Indexes in Covariance Structure Analysis: Conventional Criteria versus New Alternatives. Structural Equation Modeling: A Multidisciplinary Journal, 6, 1-55. https://doi.org/10.1080/10705519909540118

Jackson, S. A., \& Eklund, R. C. (2002). Assessing Flow in Physical Activity: The Flow State Scale-2 and Dispositional Flow Scale-2. Journal of Sport and Exercise Psychology, 24, 133-150. https://doi.org/10.1123/jsep.24.2.133

Jackson, S. A., \& Marsh, H. W. (1996). Development and Validation of a Scale to Measure Optimal Experience: The Flow State Scale. Journal of Sport and Exercise Psychology, 18, 17-35. https://doi.org/10.1123/jsep.18.1.17

Jackson, S. A., Ford, S. K., Kimiecik, J. C., \& Marsh, H. W. (1998). Psychological Corre- 
lates of Flow in Sport. Journal of Sport and Exercise Psychology, 20, 358-378. https://doi.org/10.1123/jsep.20.4.358

Kaiser, H. F. (1958). The Varimax Criterion for Analytic Rotation in Factor Analysis. Psychometrika, 23, 187-200. https://doi.org/10.1007/BF02289233

Kiili, K., \& Lainema, T. (2008). Foundation for Measuring Engagement in Educational Games. Journal of Interactive Learning Research, 19, 469-488.

Maneesriwongul, W., \& Dixon, J. K. (2004). Instrument Translation Process: A Methods Review. Journal of Advanced Nursing, 48, 175-186. https://doi.org/10.1111/j.1365-2648.2004.03185.x

Martin, A. J., \& Jackson, S. A. (2008). Brief Approaches to Assessing Task Absorption and Enhanced Subjective Experience: Examining "Short" and "Core" Flow in Diverse Performance Domains. Motivation and Emotion, 32, 141-157. https://doi.org/10.1007/s11031-008-9094-0

Mayers, P. (1978). Flow in Adolescence and Its Relation to School Experience. Unpublished Doctoral Dissertation, Chicago, IL: University of Chicago.

McDonald, R. P. (1970). The Theoretical Foundations of Principal Factor Analysis, Canonical Factor Analysis, and Alpha Factor Analysis. British Journal of Mathematical and Statistical Psychology, 23, 1-21. https://doi.org/10.1111/j.2044-8317.1970.tb00432.x

Messing, S., Rütten, A., Abu-Omar, K., Ungerer-Röhrich, U., Goodwin, L., Burlacu, I., \& Gediga, G. (2019). How Can Physical Activity Be Promoted among Children and Adolescents? A Systematic Review of Reviews across Settings. Frontiers in Public Health, 7, 55. https://doi.org/10.3389/fpubh.2019.00055

Naceur, A. (2010). Quand l'émotion perçoit et décide: Un paradigme se construit. In $D u$ percept à la décision (pp. 25-49). De Boeck Supérieur. https://doi.org/10.3917/dbu.masmo.2010.01.0025

Naceur, A., \& Schiefele, U. (2005). Motivation and Learning-The Role of Interest in Construction of Representation of Text and Long-Term Retention: Inter- and Intraindividual Analyses. European Journal of Psychology of Education, 20, 155-170. https://doi.org/10.1007/BF03173505

Narayanan, L., Abdelrasheed, N. S. G., Nasser, R. N., \& Menon, S. (2020). Dimensional Structure of the Arabic Positive Affect and Negative Affect Scale Adapted from Its English Form. Psychological Reports, 123, 2597-2616.

https://doi.org/10.1177/0033294119863293

Nunnally, J. C., \& Bernstein, I. H. (1994). The Assessment of Reliability. Psychometric Theory, 3, 248-292.

Oh, M., Zhang, D., Whitaker, K. M., Letuchy, E. M., Janz, K. F., \& Levy, S. M. (2020). Moderate-to-Vigorous Intensity Physical Activity Trajectories during Adolescence and Young Adulthood Predict Adiposity in Young Adulthood: The Iowa Bone Development Study. Journal of Behavioral Medicine, 44, 231-240. https://doi.org/10.1007/s10865-020-00190-X

Payne, B. R., Jackson, J. J., Noh, S. R., \& Stine-Morrow, E. A. (2011). In the Zone: Flow State and Cognition in Older Adults. Psychology and Aging, 26, 738. https://doi.org/10.1037/a0022359

Rheinberg, F., Vollmeyer, R., \& Engeser, S. (2003). Die erfassung des flow-erlebens.

Rijavec, M., \& Belina, L. (2018). Flow in Academic Activities at the Faculty: A Qualitative Analysis. In S. Nakić Radoš (Ed.), Protection and Promotion of the Well-Being of Children, Youth, and Families: Selected Proceedings of the 1st International Scientific Confer-ence of the Department of Psychology at the Catholic University of Croatia 
(pp. 79-92). Zagreb: Catholic University of Croatia.

Rijavec, M., Ljubin Golub, T., \& Olčar, D. (2016). Can Learning for Exams Make Students Happy? Faculty Related and Faculty Unrelated Flow Experiences and Well-Being. Croatian Journal of Education, 18, 153-164. https://doi.org/10.15516/cje.v18i0.2223

Rodriguez-Ayllon, M., Cadenas-Sánchez, C., Estévez-López, F., Muñoz, N. E., Mora-Gonzalez, J., Migueles, J. H. et al. (2019). Role of Physical Activity and Sedentary Behavior in the Mental Health of Preschoolers, Children and Adolescents: A Systematic Review and Meta-Analysis. Sports Medicine, 49, 1383-1410.

https://doi.org/10.1007/s40279-019-01099-5

Salanova, M., Bakker, A. B., \& Llorens, S. (2006). Flow at Work: Evidence for an Upward Spiral of Personal and Organizational Resources. Journal of Happiness Studies, 7, 1-22. https://doi.org/10.1007/s10902-005-8854-8

Schumacker, R. E., \& Lomax, R. G. (2004). A Beginner's Guide to Structural Equation Modeling. New York: Psychology Press. https://doi.org/10.4324/9781410610904

Sember, V., Morrison, S. A., Jurak, G., Kovač, M., Golobič, M., Samardžija, P. P. et al. (2018). Results from Slovenia's 2018 Report Card on Physical Activity for Children and Youth. Journal of Physical Activity and Health, 15, S404-S405. https://doi.org/10.1123/jpah.2018-0542

Shernoff, D. J., \& Csikszentmihalyi, M. (2009). Cultivating Engaged Learners and Optimal Learning Environments. In Handbook of Positive Psychology in Schools (pp. 131-145).

Suk, I. B., \& Kang, E. C. (2007). Development and Validation of the Learning Flow Scale. Journal of Educational Technology, 23, 121-154. https://doi.org/10.17232/KSET.23.1.121

Tabachnick, B. G., \& Fidell, L. S. (2007). Experimental Designs Using ANOVA (p. 724). Belmont, CA: Thomson/Brooks/Cole.

Vollmeyer, R., \& Rheinberg, F. (2006). Motivational Effects on Self-Regulated Learning with Different Tasks. Educational Psychology Review, 18, 239-253. https://doi.org/10.1007/s10648-006-9017-0

Wilson, B., \& Barnett, L. M. (2020). Physical Activity Interventions to Improve the Health of Children and Adolescents in Out of Home Care-A Systematic Review of the Literature. Children and Youth Services Review, 110, 104765. https://doi.org/10.1016/j.childyouth.2020.104765

Witmer, B. G., \& Singer, M. J. (1998). Measuring Presence in Virtual Environments: A Presence Questionnaire. Presence, 7, 225-240. https://doi.org/10.1162/105474698565686 


\section{Annex}

\section{The Flow scale related to Physical Education}

\begin{tabular}{|c|c|c|}
\hline & Flow items in the Arabic language & Flow items translated in English \\
\hline 1 & اشعر بالقدرة على التعامل مع المتطلبات العالية للوضعية. & $\begin{array}{l}\text { I feel I can meet the high demands of the } \\
\text { situation. }\end{array}$ \\
\hline 2 & اشعر انني اتحكم في افعالي تماما. & I feel that what I do is under my control. \\
\hline 3 & في كل مرحلة، اعرف ما الذي يجب على فعله. & $\begin{array}{l}\text { I know what I must do at every step of the } \\
\text { task. }\end{array}$ \\
\hline 4 & انا مستو عب نماما ما اقوم به. & I am totally absorbed in what Iam doing \\
\hline 5 & انا أركز بعمق على ما اقوم به. & $\begin{array}{l}\text { I am deeply concentered on what I'm } \\
\text { doing. }\end{array}$ \\
\hline 6 & انا لا ارى الوقت يمر. & I do not notice the time passing. \\
\hline 7 & انا لست منشغلا بشأن ما قد يفكر فيه الاخرون عني. & $\begin{array}{l}\text { I did not care about what the others could } \\
\text { think of me. }\end{array}$ \\
\hline 8 & انا لست منشغلا بحكم الاخرين. & I don't fear the judgment of others \\
\hline 9 & انا لست قلقا يشان ما قد يفكر فيه الاخرون عني. & $\begin{array}{l}\text { I was not worrying about what the others } \\
\text { think about me. }\end{array}$ \\
\hline 10 & لدي شعور بان اعيش لحظة بحماس. & $\begin{array}{l}\text { I have the feeling of living a moment of } \\
\text { excitement. }\end{array}$ \\
\hline 11 & هذا النشاط يعطيني الكثير من الرفاهية. & This activity makes me happy \\
\hline 12 & عندما اتحدث عن هذا النشاط، اشعر بعاطفة ارغب في مشاركتها. & $\begin{array}{l}\text { When I talk about this activity, I feel a } \\
\text { strong emotion and I want to share it. }\end{array}$ \\
\hline
\end{tabular}

